\title{
Energy Content of Young Alewives in Eastern Lake Michigan and Muskegon Lake, a Connected Drowned River Mouth Lake
}

\author{
TOMAs O. HöÖK* \\ Department of Forestry and Natural Resources, Purdue University, 195 Marstellar Street, West Lafayette, \\ Indiana 47907, USA, and Cooperative Institute for Limnology and Ecosystem Research, \\ University of Michigan, and National Oceanic and Atmospheric Administration, Great Lakes Environmental \\ Research Laboratory, 2205 Commonwealth Boulevard, Ann Arbor, Michigan 48105, USA

\section{Steven A. Pothoven} \\ National Oceanic and Atmospheric Administration, Great Lakes Environmental Research Laboratory, \\ 1431 Beach Street, Muskegon, Michigan 49441, USA
}

\begin{abstract}
Energy content is an important determinant of an individual fish's condition and a key input variable for bioenergetics applications. Energy content of young fish can change rapidly during ontogeny; given the numerical abundance and high mass-specific metabolic rates of young fish, it is particularly important to obtain detailed information on their energy content. To this end, we quantified the total body energy content and energy density of economically and ecologically important young (age-0-1) nonnative alewives Alosa pseudoharengus collected during 1998-2003 in eastern Lake Michigan and Muskegon Lake, a connected drowned river mouth lake. Our analysis demonstrates that energy content of young alewives varies across years, seasons, lakes, and ontogeny. Consistent with previous observations of size-dependent overwinter mortality, young alewives deplete a large amount of body energy between late fall and late spring (i.e., declines in length-specific energy content and energy density occur overwinter). Interestingly, unlike several past studies of young fish in their native range, size-specific energy content of young alewives does not appear to increase over the summer and fall (there is no evidence of increased energy storage in preparation for the resource-scarce winter period). Finally, our measured values are similar to the few previously published energy density values for age- 0 alewives. The high degree of variation in the energy content of young fish emphasizes the necessity of using appropriate energy measures for bioenergetics applications to inform fisheries management.
\end{abstract}

Energy content is a useful metric of physiological status of fishes and may help elucidate spatial and temporal variation in vital rates (growth and mortality). Similarly, energy density (energy per unit wet weight) is an important input variable for the application of bioenergetics models (Hanson et al. 1997), and predictions emanating from such models are sensitive to input data on energy densities of both predators and prey. Detailed information on the energy content of young fish is particularly critical. Energy content can change rapidly during early ontogeny (e.g., Wuenschel et al. 2006); due to the numerical abundance and high mass-specific consumption rates of young fish, early life stages can play important roles as both predator and prey within ecosystems.

Seasonal and ontogenetic patterns of energy content can provide insight as to how a fish population has adapted to a particular environment. Northern temperate-zone fish live in seasonal environments in which

* Corresponding author: thook@purdue.edu

Received January 19, 2008; accepted September 17, 2008 Published online March 30, 2009 conditions for growth and survival vary throughout the year. For young temperate-zone fish, there are seasonspecific trade-offs between energy allocation to different tissue types (low energy density structural tissue versus high energy density storage tissue) that have clear consequences for survival. During summer and early fall, size-selective predation pressure is often high and prey resources are abundant; thus, summer survival is probably enhanced by increased energy allocation to structural tissue. On the other hand, winters are often characterized by relatively low predation pressure and relatively low foraging opportunities; therefore, winter survival is likely to increase with higher energy allocation to storage tissues. Several past studies have examined how young fish allocate energy in a seasonal environment (e.g., Schultz and Conover 1997; Post and Parkinson 2001; Metcalfe et al. 2002; Garvey and Marschall 2003; Hurst and Conover 2003; Biro et al. 2004). As expected, these studies generally demonstrate that during the early growing season, young fish preferentially allocate surplus energy to somatic (i.e., structural) growth, whereas as winter approaches, they shift energy allocation towards storage (Metcalfe et al. 2002; Hurst 
and Conover 2003). In addition, energy allocation strategies appear to vary across latitudes; populations at higher latitudes (i.e., where winters are longer and more severe) allocate more energy towards storage prior to winter (Schultz and Conover 1997; Garvey and Marschall 2003).

In Lake Michigan, the invasive alewife Alosa pseudoharengus is a key component of the ecosystem that (1) constitutes the primary prey of salmon and trout (which in turn support economically important recreational fisheries; Madenjian et al. 2002), (2) is capable of restructuring zooplankton communities (Brooks and Dodson 1965; Wells 1970; Hewett and Stewart 1989), and (3) influences, through competition and predation, the dynamics of several native species (e.g., yellow perch Perca flavescens, emerald shiner Notropis atherinoides, and lake trout Salvelinus namaycush; Madenjian et al. 2008). Studies on the energy dynamics of young alewives are few in number and include measures of alewives collected prior to some dramatic changes to the Lake Michigan ecosystem. These changes include the invasion and proliferation of zebra mussels Dreissena polymorpha and quagga mussels $D$. bugensis and the collapse of the native amphipods Diporeia spp., which are important prey for alewives (Pothoven and Madenjian 2008). In fact, there is only one published energy density measure that definitively represents an age- 0 alewife: $5,020 \mathrm{~J} / \mathrm{g}$ wet weight was measured for individuals (mean total length $=48.5 \mathrm{~mm}$ ) collected during October 1979-1981 (Flath and Diana 1985; Stewart and Binkowski 1986). When simulating growth and consumption of Lake Michigan alewives, other authors have made assumptions regarding age-0 alewife energy densities (Stewart and Binkowski 1986; Hewett and Stewart 1989; Höök et al. 2008). Based on measures of age-1 alewives, Stewart and Binkowski (1986) assumed that on $1 \mathrm{July}, 31-\mathrm{mm}$, age-0 alewives have an energy density of $4,185 \mathrm{~J} / \mathrm{g}$ wet weight (i.e., $1 \mathrm{kcal} / \mathrm{g}$ ). Based on data from Pacific herring Clupea pallasii, Hewett and Stewart (1989) assumed that age-0 alewife energy density increased linearly from $2,511 \mathrm{~J} / \mathrm{g}$ wet weight at hatching to $4,185 \mathrm{~J} / \mathrm{g}$ wet weight at $31 \mathrm{~d}$ posthatch.

It is clear that adult alewife energy densities vary seasonally: increases in individual energy densities occur during late summer and fall, and decreases in energy densities occur overwinter (Flath and Diana 1985; Stewart and Binkowski 1986; Rand et al. 1994; Madenjian et al. 2006). More recently, analysis of adult alewives (collected during 2002-2004) by Madenjian et al. (2006) indicated that although adult alewife energy densities continue to vary seasonally, mean season-specific adult alewife energy densities have decreased by $23 \%$ over 23 years (from approximately 1979 to 2002). These changes are consistent with a recent decrease in mean condition (Fulton's $K$ ) of age-1 and older alewives (Madenjian et al. 2003) and are probably attributable to various ecosystem-level changes within Lake Michigan. Seasonal and ontogenetic energy dynamics of young alewives are not fully described; however, given that young alewives experience the same seasonal environment as adults, it is likely that young alewives also exhibit seasonal energy dynamics. Thus, survival conditions for age- 0 alewives in Lake Michigan are likely to vary seasonally (sizedependent mortality over summer: Mansfield and Jude 1986; likely size-dependent starvation overwinter: Höök et al. 2007). Such seasonal dynamics suggest that similar to several fish species in their native range, young alewives in Lake Michigan may adopt a seasonspecific energy allocation strategy.

Herein, we document energy dynamics of young alewives in eastern Lake Michigan and Muskegon Lake in relation to individual length, season, year, and lake. Second, we evaluate whether energy content of young alewives has changed dramatically over the 23 years (1979-2003) and whether seasonal energy allocation patterns of this invasive species are consistent with expectations based on various other studies of fish species in their native range.

\section{Methods}

During 1998-2003, age-0 (August-November) and age-1 (March-July) alewives were collected via bottom and midwater trawling in eastern Lake Michigan (in the vicinity of Muskegon, Michigan). During 2002 (JulyNovember), age-0 alewives were also collected via midwater trawling in Muskegon Lake, a drowned river mouth lake draining into Lake Michigan. Detailed descriptions of these collections are presented elsewhere (Hondorp et al. 2005; Höök et al. 2007). Upon collection, young alewives were immediately frozen. In the laboratory, individual alewives were thawed, and total length (nearest $1 \mathrm{~mm}$ ) and wet weight (nearest $0.01 \mathrm{~g})$ were measured. Individual alewives were placed whole (or cut into several small pieces) into aluminum drying tins, dried for $3 \mathrm{~d}$ at $70^{\circ} \mathrm{C}$ (Lantry and O'Gorman 2007), and reweighed (nearest $0.01 \mathrm{~g}$ ). Individual dried alewives were then homogenized with a mortar and pestle, and whole homogenized fish (or a 1-g subsample for fish with dry weights $>1 \mathrm{~g}$ ) were individually combusted in a Parr 1261 isoperibol calorimeter standardized with benzoic acid. In turn, we calculated individual alewives' proportional dry weight to wet weight, energy density (based on both wet and dry weights), and total body energy content $(\mathrm{J} / \mathrm{g}$ dry weight $\times$ total dry weight). Although analysis 
of small, whole alewives prevented determination of measurement repeatability, past analyses demonstrate that for energy density the coefficient of variation (100 $\times \mathrm{SD} /$ mean) of our method is low $(1.03 \%$; Madenjian et al. 2006).

We did not individually age all young alewives; we used length-at-age information (e.g., Madenjian et al. 2003) to classify fall-caught individuals as age-0 if their total length was less than $100 \mathrm{~mm}$. Similarly, allowing for some growth during winter and early spring, we assumed that if a spring-collected individual was smaller than $110 \mathrm{~mm}$ total length, then it was age 1. Although the 110-mm cutoff for spring-caught age-1 alewives is fairly conservative, it is feasible that some age- 1 fish in fall could be smaller than $100 \mathrm{~mm}$. However, the majority of fall-collected age- 0 alewives between 90 and $100 \mathrm{~mm}$ were collected in Muskegon Lake, a habitat that alewives appear to exclusively utilize as spawning and nursery grounds (i.e., age-1 alewives are highly unlikely to occupy Muskegon Lake; Höök et al. 2007). In Lake Michigan, only seven 90-mm and larger individuals (and only one individual larger than $95 \mathrm{~mm}$ ) were classified as age 0 .

To evaluate seasonal and ontogenetic patterns of energy dynamics, we compared allometric relationships (data grouped by year, month, and lake) between total length $(L)$ in millimeters and total body energy $(E)$ in joules as

$$
E=a L^{b}
$$

where $a$ and $b$ are the allometric parameters. We believe that length-specific total body energy content is a particularly useful index of condition for two reasons: (1) this measure encapsulates both length-specific tissue composition and weight (both of which influence condition) and (2) when analyzing small fish that have been frozen for different durations, condition indices based in part on accurate measures of wet weight (e.g., energy per unit wet weight) may be biased due to some unavoidable drying during freezing.

Previous studies suggest that $a$ and $b$ from the allometric relation provide insight as to seasonal and ontogenetic patterns of energy allocation (e.g., Hurst and Conover 2003). We evaluated the homogeneity of slopes relating $\log _{e} E$ to $\log _{e} L$ using indicator variables (Neter et al. 1996) and used analysis of covariance (ANCOVA) to compare adjusted mean energy content (adjusted to mean length). We initially grouped samples by year, month, and lake of capture. For 3 months (October, May, and June), there were sufficient samples from Lake Michigan to allow comparisons across years of month-specific allometric relationships. In addition, for each year-class (1997-2002), we compared allometric relationships among months of capture. Similarly, we combined Lake Michigan data across years and used this larger data set to compare allometric relationships among months. Further, for 2002, we compared month-specific relationships between Muskegon Lake and Lake Michigan. All statistical comparisons were based on a significance level $\alpha$ equal to 0.05 . Finally, we qualitatively compared energy density patterns of age- 0 alewives from 1998 to 2003 (1997-2002 year-classes) with previously published measured and assumed values (Flath and Diana 1985; Stewart and Binkowski 1986; Hewett and Stewart 1989).

\section{Results}

We quantified size, energy density, and energy content of 455 young alewives (Table 1). For statistical analyses, we excluded measurements from months with low samples sizes $(n<6)$, and we excluded six individuals with frayed caudal fins for which we could not quantify total length (4 fish from October 2001 and 2 fish from May 2002). Nonetheless, individual length was a strong determinant of total energy content, and the relationship between individual length and total energy content was consistently allometric (i.e., $b>3$; Figure 1). In addition, after accounting for the effect of length, it is apparent that various factors (year, season, and lake) influence the energy content of young alewives (Figure 2).

Temporal variation in energy content was largely attributable to seasonal effects, but some annual effects were also evident. Although month-specific $b$-values did not differ significantly among years, we found significant annual differences in length-adjusted energy content for October $\left(F_{2,99}=6.5, P=0.002\right)$ and June $\left(F_{2,64}=6.2, P=0.002\right.$; Figure 2).

For most year-classes, $b$ did not differ significantly among months. However, during 2002 and with data combined across years, $b$ differed significantly between October and November (2002: $P<0.001$; all data: $P$ $<0.001)$. Although these differences in $b$ confound comparisons among length-adjusted energy content for the 2002 year-class and for data combined across years, comparisons for other year-classes are more straightforward (1997: $F_{1,18}=0.7, P=0.40 ; 1998: F_{2,36}=7.2$, $P=0.002$; 2001: $F_{1,45}=7.2, P=0.01$; Figure 3 ). For the 2002 data set and for data combined across years, monthly values of $b$ were not significantly different when November data were excluded. Thus, for these two data sets, we also used ANCOVA to compare monthly length-adjusted energy content among October, May, and June, and in so doing we found significant effects by month (2002: $F_{1,93}=83.7, P<$ 0.001 ; all years: $F_{2,201}=57.0, P<0.001$; Figure 3 ). 
TABLE 1.-Monthly mean ( \pm SE) total length (TL), wet weight (WW), dry weight (DW) : WW ratio, and energy content of individual young alewives $(n=455)$ collected in Lake Michigan and Muskegon Lake, Michigan. Year-class (1997-2002) is given in parentheses.

\begin{tabular}{|c|c|c|c|c|c|c|}
\hline $\begin{array}{l}\text { Collection } \\
\text { month and year }\end{array}$ & $n$ & $\mathrm{TL}(\mathrm{mm})$ & WW (g) & DW : WW (g/g) & $\begin{array}{l}\text { Energy density } \\
(\mathrm{J} / \mathrm{g} \text { wet weight })\end{array}$ & $\begin{array}{l}\text { Total body } \\
\text { energy }(J)\end{array}$ \\
\hline \multicolumn{7}{|c|}{ Lake Michigan (1997) } \\
\hline May 1998 & 14 & $75.2 \pm 3.4$ & $2.48 \pm 0.54$ & $0.25 \pm 0.01$ & $5,323 \pm 290$ & $14,551 \pm 4,281$ \\
\hline Jun 1998 & 7 & $88.1 \pm 5.8$ & $3.82 \pm 0.71$ & $0.24 \pm 0.01$ & $5,268 \pm 534$ & $21,390 \pm 5,856$ \\
\hline \multicolumn{7}{|c|}{ Lake Michigan (1998) } \\
\hline Oct 1998 & 12 & $71.4 \pm 5.0$ & $2.67 \pm 0.58$ & $0.25 \pm 0.01$ & $5,566 \pm 343$ & $16,345 \pm 4,113$ \\
\hline May 1999 & 14 & $86.0 \pm 3.9$ & $4.21 \pm 0.54$ & $0.25 \pm 0.01$ & $5,616 \pm 282$ & $24,480 \pm 3,448$ \\
\hline Jun 1999 & 14 & $82.7 \pm 3.4$ & $3.63 \pm 0.49$ & $0.22 \pm 0.01$ & $4,724 \pm 238$ & $17,481 \pm 2,958$ \\
\hline \multicolumn{7}{|c|}{ Lake Michigan (2001) } \\
\hline Oct 2001 & 46 & $61.9 \pm 1.6$ & $1.45 \pm 0.17$ & $0.33 \pm 0.01$ & $5,162 \pm 131$ & $7,880 \pm 1,182$ \\
\hline May 2002 & 8 & $80.7 \pm 4.8$ & $3.05 \pm 0.72$ & $0.27 \pm 0.01$ & $4,511 \pm 380$ & $15,053 \pm 5,181$ \\
\hline \multicolumn{7}{|c|}{ Lake Michigan (2002) } \\
\hline Oct 2002 & 49 & $61.3 \pm 1.3$ & $1.73 \pm 0.12$ & $0.24 \pm 0.01$ & $4,568 \pm 112$ & $8,218 \pm 715$ \\
\hline Nov 2002 & 46 & $61.2 \pm 2.0$ & $1.80 \pm 0.20$ & $0.29 \pm 0.01$ & $4,289 \pm 171$ & $9,129 \pm 1,358$ \\
\hline Jun 2003 & 47 & $84.1 \pm 1.9$ & $3.71 \pm 0.28$ & $0.25 \pm 0.01$ & $3,668 \pm 143$ & $14,884 \pm 1,717$ \\
\hline \multicolumn{7}{|c|}{ Lake Michigan (1997-2002) } \\
\hline Oct & 107 & $62.7 \pm 1.1$ & $1.72 \pm 0.12$ & $0.28 \pm 0.01$ & $4,936 \pm 91$ & $8,984 \pm 789$ \\
\hline Nov & 46 & $61.2 \pm 2.0$ & $1.80 \pm 0.20$ & $0.29 \pm 0.01$ & $4,289 \pm 171$ & $9,129 \pm 1,358$ \\
\hline May & 36 & $80.6 \pm 2.4$ & $3.28 \pm 0.35$ & $0.25 \pm 0.01$ & $5,256 \pm 187$ & $18,524 \pm 2,491$ \\
\hline Jun & 68 & $84.2 \pm 1.6$ & $3.71 \pm 0.23$ & $0.24 \pm 0.004$ & $4,050 \pm 141$ & $16,088 \pm 1,459$ \\
\hline \multicolumn{7}{|c|}{ Muskegon Lake (2002) } \\
\hline Jul 2002 & 6 & $46.6 \pm 3.6$ & $0.96 \pm 0.19$ & $0.24 \pm 0.01$ & $4,388 \pm 411$ & $4,587 \pm 1,227$ \\
\hline Aug 2002 & 12 & $71.8 \pm 1.3$ & $2.85 \pm 0.19$ & $0.32 \pm 0.01$ & $6,891 \pm 120$ & $19,735 \pm 1,478$ \\
\hline Sep 2002 & 60 & $72.7 \pm 1.1$ & $2.99 \pm 0.12$ & $0.29 \pm 0.003$ & $6,185 \pm 115$ & $18,949 \pm 936$ \\
\hline Oct 2002 & 57 & $84.1 \pm 0.7$ & $4.50 \pm 0.10$ & $0.28 \pm 0.004$ & $5,919 \pm 84$ & $26,826 \pm 848$ \\
\hline Nov 2002 & 53 & $86.3 \pm 0.8$ & $4.71 \pm 0.13$ & $0.27 \pm 0.003$ & $5,820 \pm 79$ & $27,658 \pm 967$ \\
\hline
\end{tabular}

Within annual cohorts, seasonal changes in energy content were evident overwinter. Interestingly, mean total body energy tended to increase overwinter (Table 1), but length-specific energy content decreased significantly from autumn to spring and continued to decline from May to June (Figures 1A, 3).

Similar to patterns in Lake Michigan (described above), during 2002 there were strong seasonal patterns in energy content of young alewives captured in Muskegon Lake. Data for age-0 alewives from Muskegon Lake are informative because they span most of the growing season (July-November). Although $b$ did not vary significantly among months, the mean length-adjusted energy content of fish in Muskegon Lake was significantly higher during the summer than during autumn $\left(F_{4,182}=16.9, P<0.001\right.$; Figures 1B, 4). Further, during October (but not November) 2002, length-adjusted energy content of young alewives was significantly higher in Muskegon Lake than in Lake Michigan (October: $F_{1,103}=8.8, P=$ 0.004; November: $F_{1,96}=0.5, P=0.47$; Figure 4).

Finally, we compared our results with previously published energy density and total body energy content values for young alewives (derived from Flath and Diana 1985; Stewart and Binkowski 1986; Hewett and
Stewart 1989; Figures 1, 5). These comparisons are qualitative because we cannot quantify the uncertainty associated with previously published values and because only one of these values represents the measured energy of an actual age- 0 alewife while other published values are based on assumed values. Nonetheless, although our measures of age- 0 alewife energy density appear to be slightly lower than previously published values, our measures of age-1 energy content are not consistently different from previously published measured and assumed values (Figures 3, 4).

\section{Discussion}

Energy content of young alewives appears to vary dramatically across ontogeny, season, year, and habitat. Given the importance of young alewives as predators (e.g., Hewett and Stewart 1989; Pothoven and Vanderploeg 2004) and prey (Jude et al. 1987; Stewart and Ibarra 1991), the information presented herein should prove useful for future bioenergetics-based studies of Great Lakes ecosystems. Predictions from bioenergetics models are sensitive to input values of predator and prey energy densities, and thus the high degree of variation in energy content of young alewives 

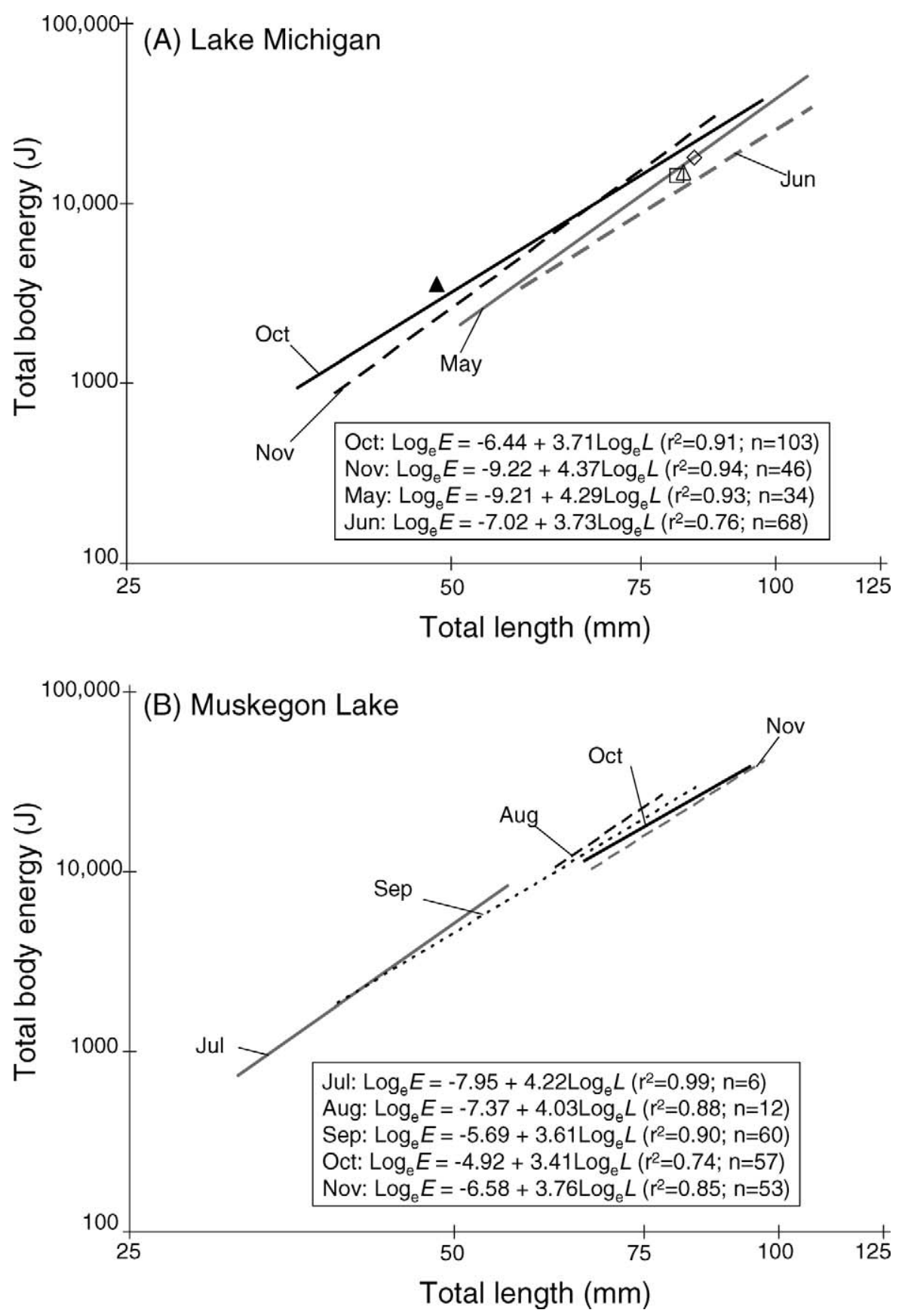

FIGURE 1.-Estimated month-specific allometric relationships between total length $(L$; in $\mathrm{mm})$ and total body energy $(E$; in $\mathrm{J})$ for young alewives: $(\mathbf{A})$ age-0 fish (October = solid black line; November = dashed black line) and age-1 fish (May = solid gray line; June = dashed gray line) collected in Lake Michigan during 1998-2003 and values derived from 1979-1991 data (from Flath and Diana 1985; Stewart and Binkowski 1986) for 48.5-mm age-0 fish collected in October (solid triangle) and age-1 fish collected in April (open square), May (open triangle), and June (open diamond); and (B) age-0 fish collected in Muskegon Lake, Michigan $($ July $=$ solid gray line; August $=$ dashed black line; September $=$ dotted black line; October $=$ solid black line; November $=$ dashed gray line), during 2002. Note logarithmic scales. 


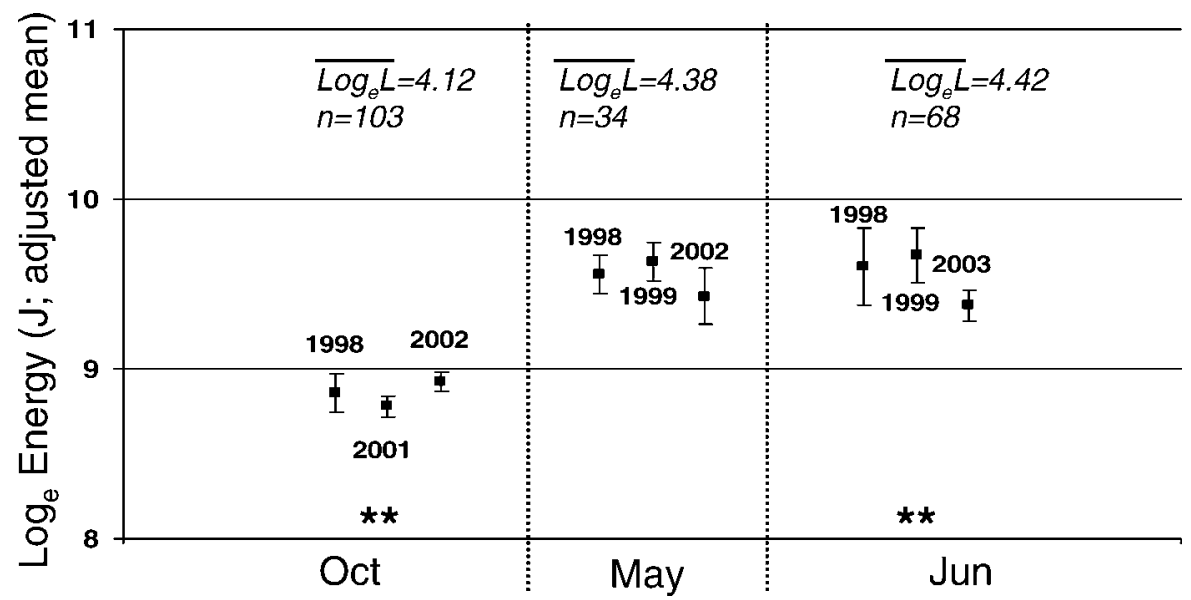

FIGURE 2.- Results of three analyses of covariance comparing total body energy ( $E$; in $\mathrm{J}$; $\log _{e}$ transformed) of young alewives among years of capture in Lake Michigan (within-month comparisons across years) with total length $\left(L\right.$; in $\mathrm{mm}$; log $\log _{e}$ transformed) as a covariate. Results are presented as mean $( \pm \mathrm{SE})$ length-adjusted $E\left(\log _{e} E\right.$ adjusted to the mean value of $\log _{e} L$ given in italics). Significant differences are identified by asterisks.

suggests that bioenergetics studies should use lengthand season-appropriate energy density values for young alewives.

Decreases in length-specific energy content of young alewives during winter were particularly noteworthy. Such seasonal energy dynamics are consistent with a high degree of size-selective overwinter mortality (Brown 1972; Flath and Diana 1985; O'Gorman and Schneider 1986; Bergstedt and O'Gorman 1989; Höök et al. 2007). That is, because smaller alewives have relatively low mass-specific energy content (i.e., $b$ relating length and energy were consistently $\geq 3$ ) and high mass-specific metabolic rates (Stewart and Binkowski 1986), they are more likely to deplete their energy stores and die. In fact, such size-selective mortality partly explains our finding that overwinter mean total body energy content increased while sizespecific energy content decreased.

It is also noteworthy that energy depletion by alewives continued into the late spring and early summer (i.e., length-specific energy content tended to be lower in June than in May; Figures 1A, 3). Although

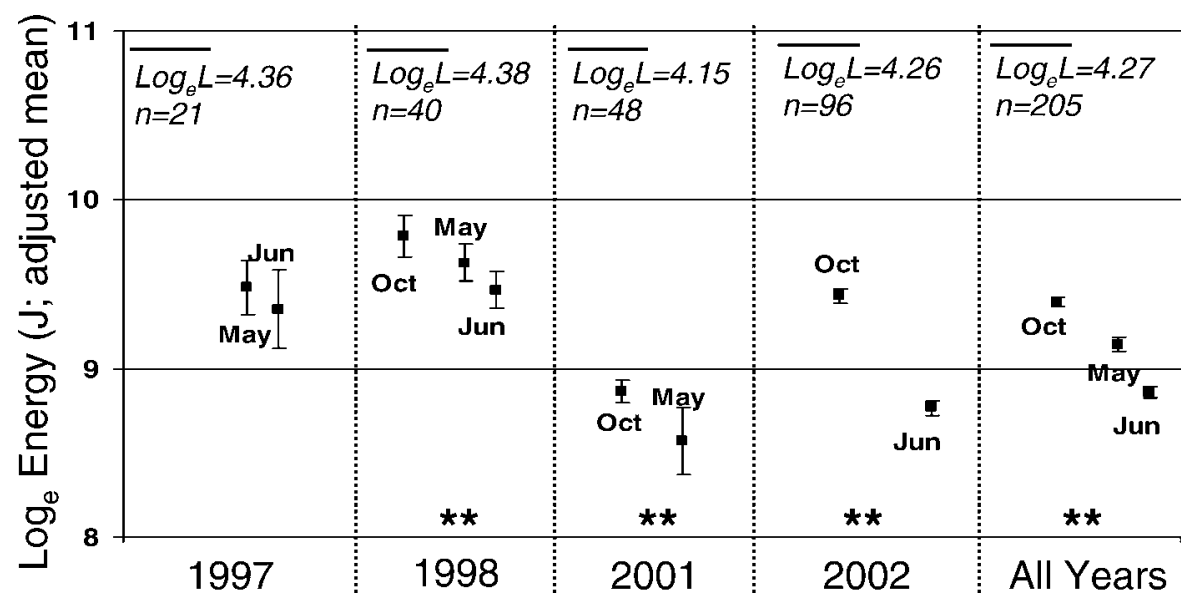

FIGURE 3.-Results of five analyses of covariance comparing total body energy ( $E$; in $\mathrm{J}$; $\log _{e}$ transformed) of young alewives among months in Lake Michigan (year-class-specific comparisons across month of capture) with total length $\left(L\right.$; in $\mathrm{mm}$; $\log _{e}$ transformed) as a covariate. Results are presented as mean $( \pm \mathrm{SE})$ length-adjusted $E\left(\log _{e} E\right.$ adjusted to the mean value of $\log _{e} L$ given in italics). Note that May and June collections from year-class $X$ were collected during year $X+1$. Significant differences are identified by asterisks. 


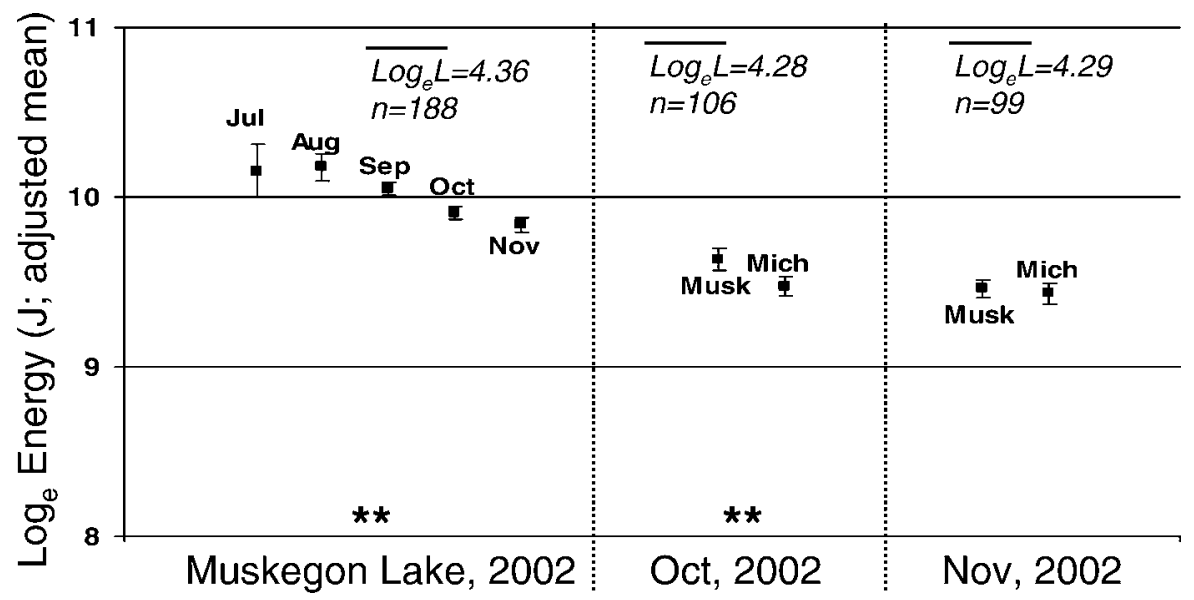

FIGURE 4.- Results of three analyses of covariance comparing total body energy ( $E$; in $\mathrm{J}$; $\log _{e}$ transformed) of young alewives (with total length $L$ [in $\mathrm{mm}$; $\log _{e}$ transformed] as a covariate) among months in Muskegon Lake, Michigan (comparisons across month of capture for the 2002 year-class), and between habitats (within-month comparisons between Muskegon Lake [Musk] and Lake Michigan [Mich], 2002). Results are presented as mean ( \pm SE) length-adjusted $E\left(\log _{e} E\right.$ adjusted to the mean value of $\log _{e} L$ given in italics). Significant differences are identified by asterisks.

the length threshold that alewives must reach to survive winter may vary by year and individual condition, various studies indicate that this threshold is approximately 60-mm total length (Brown 1972; O'Gorman et al. 1997; Höök et al. 2007). However, other studies have collected young alewives smaller than $60 \mathrm{~mm}$ during the spring. For instance, during spring 19941995, lake trout in Lake Michigan consumed a very small number of alewives between 45 and $60 \mathrm{~mm}$ (C. Madenjian, U.S. Geological Survey, Great Lakes

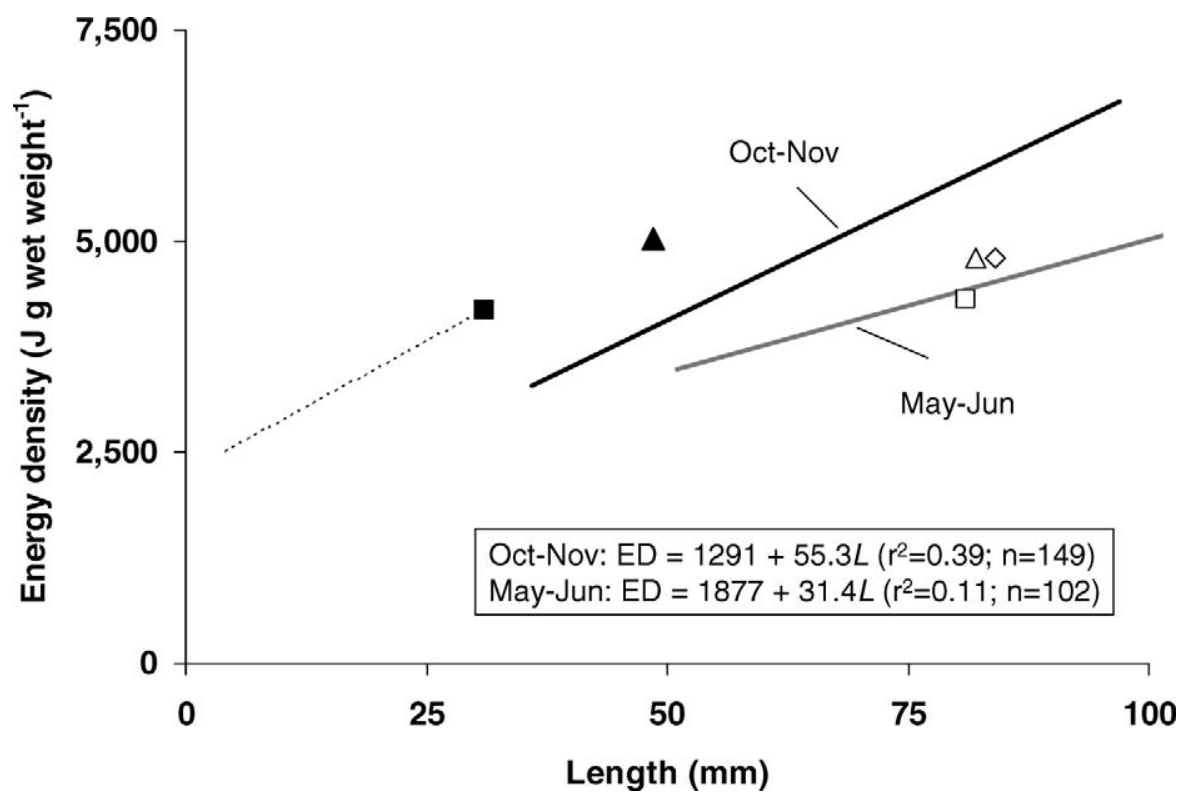

FIGURE 5.-Comparison between length $(L)$-specific energy densities (EDs; J/g wet weight) for age-0 (October-November $=$ solid black line) or age-1 (May-June = solid gray line) alewives collected during 1998-2003 and previously published energy density values for young alewives: assumed values for 4-31-mm, age-0 fish (thin dashed line; Hewett and Stewart 1989); assumed value for 31-mm, age-0 fish on 1 July (solid square; Stewart and Binkowski 1986); measured value for 48.5-mm, age-0 fish in October 1979-1981 (solid triangle; Flath and Diana 1985); and measured values for age-1 fish in April (open square), May (open triangle), and June (open diamond) 1979-1981 (Flath and Diana 1985; Stewart and Binkowski 1986). 
Science Center, personal communication; study described in Madenjian et al. 1998). Similarly, on 23 March 1999, one of us (S.A.P., unpublished data) collected 93 recently deceased young alewives in eastern Lake Michigan. These alewives ranged in length from 48 to $88 \mathrm{~mm}$, and $45 \%$ were smaller than $60 \mathrm{~mm}$. Results of the study presented herein suggest that although very small alewives may be alive during the spring (March-May), such individuals may continue to lose energy and not actually survive to summer. Similarly, during 1962-1970, trawling surveys in eastern Lake Michigan collected some age-1 alewives that were smaller than $60 \mathrm{~mm}$ in April but collected only $60-\mathrm{mm}$ and larger age-1 alewives in May (Brown 1972).

The high degree of energy depletion overwinter coupled with size-selective predation during the growing season (Mansfield and Jude 1986) suggests that like various other fish species (Schultz and Conover 1997; Post and Parkinson 2001; Metcalfe et al. 2002; Garvey and Marschall 2003; Hurst and Conover 2003; Biro et al. 2004), young alewives are likely to adopt a season-specific energy allocation strategy (i.e., preferential allocation of surplus energy to somatic [structural] growth during the early growing season, and preferential allocation to energy storage as winter approaches). We assume that age-0 alewives in Muskegon Lake subsequently overwinter in Lake Michigan (Höök et al. 2007); thus, we would expect length-specific energy content of age-0 alewives in both Muskegon Lake and Lake Michigan to increase from early summer to late fall. Due to the paucity of data from summer and early fall, we were not able to evaluate this expectation for Lake Michigan. However, our findings for Muskegon Lake are inconsistent with expectations. During 2002, length-specific energy content of alewives in Muskegon Lake decreased from July to November (Figure 4) rather than increasing as expected. Given that alewives are not native to the Lake Michigan ecosystem, this surprising pattern may partially reflect the evolution of the species in a marine habitat. Overwinter starvation is probably not as important as a mortality source in the alewife's native range (Atlantic Ocean), and thus the species may not have evolved the expected seasonal energy allocation strategy.

It is possible that ambient conditions (temperature, prey availability, and alewife abundance) are much stronger determinants of length-specific energy content than season. Höök et al. (2007) demonstrated that in Muskegon Lake during 2001 and 2002, (1) growth conditions for young alewives were superior to those present in nearshore eastern Lake Michigan and (2) densities of large-bodied zooplankton (potentially important prey for age-0 alewives) decreased during July through November. Thus, greater length-specific energy content for alewives in Muskegon Lake during October 2002 (relative to alewives in Lake Michigan) and decreasing length-specific alewife energy content in Muskegon Lake from July to November 2002 may primarily reflect differences in rearing conditions. Finally, it is also likely that interannual variation in ambient growth conditions contributed to differences in month- and length-specific energy content among annual cohorts in Lake Michigan.

Madenjian et al. (2006) suggested that energy densities of large alewives in Lake Michigan were significantly lower during 2002-2004 than previously (1979-1981; Flath and Diana 1985) and attributed this decline to dramatic changes in the Lake Michigan ecosystem. These same authors also explored energy densities of small alewives and suggested that such values were not significantly different from historical measures of young alewife energy densities. Madenjian et al. (2006) grouped alewives into size categories based on length (small, $<120 \mathrm{~mm}$; large, $>120 \mathrm{~mm}$ ) and subsequently homogenized individuals and collectively measured mean energy density for multiple individuals collected at the same time. Based on observed growth rates, it is likely the small category included both age- 0 and age- 1 alewives, while the large category included age- 1 and older individuals (Madenjian et al. 2003). The grouping of age- 0 and age- 1 alewives and the measurement of homogenates of multiple individuals provides useful information regarding the energy content of an important prey for salmon and trout. However, our analysis suggests that it is imperative to control for individual size in order to elucidate and compare energy dynamics of young alewives. Further, any comparisons between our measures and historical measures of alewife energy content (i.e., 1979-1981 data; Flath and Diana 1985; Stewart and Binkowski 1986) must be qualitative because the quantitative uncertainties surrounding these historical mean energy values are unknown (see Lantry and O'Gorman 2007).

Considering the above caveat, any conclusions regarding comparisons between our measures of length-adjusted energy content (both total body energy content and energy density) and historical measures are equivocal. Madenjian et al. (2006) primarily attributed energy density decreases in large alewives to declines in the lipid-rich Diporeia spp. that have historically constituted important prey for adult alewives (Stewart and Binkowski 1986). Further, Madenjian et al. (2006) suggested that the lack of an energy density decline in small alewives may be attributable to the fact that Diporeia spp. are not important prey for such 
diminutive fish. Our finding of slightly lower age-0 alewife length-adjusted energy content during 19982002 (as compared with 1979-1981) may suggest that the mean body condition of age- 0 alewives is responding to ecosystem changes. On the other hand, energy densities of age- 1 alewives that survived winter are not consistent with this hypothesis. Although length-adjusted energy content of June-caught fish was lower than historical measures, the opposite pattern was observed for May-caught fish.

In conclusion, it is evident that energy content of young alewives in Lake Michigan varies ontogenetically, seasonally, annually, and by habitat. In particular, our study suggests that (1) young alewives in Lake Michigan lose a large amount of energy overwinter and energy loss continues into June, (2) seasonal energy allocation patterns of age- 0 alewives observed in Muskegon Lake during summer and fall are inconsistent with expectations based on studies of other species, and (3) energy densities of young alewives from 1997 to 2002 are similar to (or perhaps slightly lower than) measures from 1979 to 1981 (Flath and Diana 1985; Stewart and Binkowski 1986; Hewett and Stewart 1989). As predictions from bioenergetics models are sensitive to input values of predator and prey energy densities, the high degree of variation revealed through this study suggests that future bioenergetics-based applications involving young alewives should utilize size- and season-specific information on energy content. In general, our results highlight that (1) measures of fish energy content are not necessarily equivalent across habitats, years, or seasons; and (2) patterns of seasonal energy allocation are not necessarily qualitatively consistent across populations. We suggest that the basis for assigning predator and prey energy densities should be critically considered when interpreting bioenergetics-based results to inform fisheries management.

\section{Acknowledgments}

We thank Anna Harrison for assistance with laboratory analysis. This manuscript benefited from comments provided by Jim Breck and Brent Murray. This work was funded by the National Oceanic and Atmospheric Administration (NOAA) Great Lakes Environmental Research Laboratory (GLERL). This is NOAA-GLERL contribution 1508.

\section{References}

Bergstedt, R. A., and R. O'Gorman. 1989. Distribution of alewives in southeastern Lake Ontario in autumn and winter: a clue to winter mortalities. Transactions of the American Fisheries Society 118:687-692.

Biro, P. A., A. E. Morton, J. R. Post, and E. A. Parkinson.
2004. Over-winter lipid depletion and mortality of age-0 rainbow trout (Oncorhynchus mykiss). Canadian Journal of Fisheries and Aquatic Sciences 61:1513-1519.

Brooks, J. L., and S. I. Dodson. 1965. Predation, body size, and composition of plankton. Science 150:28-35.

Brown, E. H., Jr. 1972. Population biology of alewives, Alosa pseudoharengus, in Lake Michigan, 1949-1970. Journal of the Fisheries Research Board of Canada 29:477-500.

Flath, L. E., and J. S. Diana. 1985. Seasonal energy dynamics of the alewife in southeastern Lake Michigan. Transactions of the American Fisheries Society 114:328-337.

Garvey, J. E., and E. A. Marschall. 2003. Understanding latitudinal trends in fish body size through models of optimal seasonal energy allocation. Canadian Journal of Fisheries and Aquatic Sciences 60:938-948.

Hanson, P. C., T. B. Johnson, D. E. Schindler, and J. F. Kitchell. 1997. Fish bioenergetics 3.0. University of Wisconsin, Center for Limnology, Madison.

Hewett, S. W., and D. J. Stewart. 1989. Zooplanktivory by alewives in Lake Michigan: ontogenetic, seasonal, and historical patterns. Transactions of the American Fisheries Society 118:581-596.

Hondorp, D. W., S. A. Pothoven, and S. B. Brandt. 2005. Influence of Diporeia density on diet composition, relative abundance, and energy density of planktivorous fishes in southeast Lake Michigan. Transactions of the American Fisheries Society 134:588-601.

Höök, T. O., E. S. Rutherford, T. E. Croley, D. M. Mason, and C. P. Madenjian. 2008. Annual variation in habitatspecific recruitment success: implications from an individual-based model of Lake Michigan alewife (Alosa pseudoharengus). Canadian Journal of Fisheries and Aquatic Sciences 65:1402-1412.

Höök, T. O., E. S. Rutherford, D. M. Mason, and G. S. Carter. 2007. Hatch dates, growth, survival and over-winter mortality of age-0 alewives in Lake Michigan: implications for habitat-specific recruitment success. Transactions of the American Fisheries Society 136:1298-1312.

Hurst, T. P., and D. O. Conover. 2003. Seasonal and interannual variation in the allometry of energy allocation in juvenile striped bass. Ecology 84:3360-3369.

Jude, D. J., F. J. Tesar, S. F. Deboe, and T. J. Miller. 1987. Diet and selection of major prey species by Lake Michigan salmonines, 1973-1982. Transactions of the American Fisheries Society 116:677-691.

Lantry, B. F., and R. O'Gorman. 2007. Drying temperature effects on fish dry mass measurements. Journal of Great Lakes Research 33:606-616.

Madenjian, C. P., T. J. DeSorcie, and R. M. Stedman. 1998. Ontogenetic and spatial patterns in diet and growth of lake trout in Lake Michigan. Transactions of the American Fisheries Society 127:236-252.

Madenjian, C. P., G. L. Fahnenstiel, T. H. Johengen, T. F. Nalepa, H. A. Vanderploeg, G. W. Fleischer, P. J. Schneeberger, D. M. Benjamin, E. B. Smith, J. R. Bence, E. S. Rutherford, D. S. Lavis, D. M. Robertson, D. J. Jude, and M. P. Ebener. 2002. Dynamics of the Lake Michigan food web, 1970-2002. Canadian Journal of Fisheries and Aquatic Sciences 59:736-753.

Madenjian, C. P., J. D. Holuszko, and T. J. Desorcie. 2003. Growth and condition of alewives in Lake Michigan, 
1984-2001. Transactions of the American Fisheries Society 132:1104-1116.

Madenjian, C. P., R. O’Gorman, D. B. Bunnell, R. L. Argyle, E. F. Roseman, D. M. Warner, J. D. Stockwell, and M. A. Stapanian. 2008. Adverse effects of alewives on Laurentian Great Lakes fish communities. North American Journal of Fisheries Management 28:263-282.

Madenjian, C. P., S. A. Pothoven, J. M. Dettmers, and J. D. Holuszko. 2006. Changes in seasonal energy dynamics of alewife (Alosa pseudoharengus) in Lake Michigan after invasion of dreissenid mussels. Canadian Journal of Fisheries and Aquatic Sciences 63:891-902.

Mansfield, P. J., and D. J. Jude. 1986. Alewife (Alosa pseudoharengus) survival during the first growth season in southeastern Lake Michigan. Canadian Journal of Fisheries and Aquatic Sciences 43:1318-1326.

Metcalfe, N. B., C. D. Bull, and M. Mangel. 2002. Seasonal variation in catch-up growth reveals state-dependent somatic allocations in salmon. Evolutionary Ecology Research 4:871-881.

Neter, J., M. H. Kutner, C. J. Nachtsheim, and W. Wasserman. 1996. Applied linear statistical methods, 4th edition. McGraw-Hill, Boston.

O'Gorman, R., O. E. Johansson, and C. P. Schneider. 1997. Age and growth of alewives in the changing pelagia of Lake Ontario, 1978-1992. Transactions of the American Fisheries Society 126:112-126.

O'Gorman, R., and C. P. Schneider. 1986. Dynamics of alewives in Lake Ontario following a mass mortality. Transactions of the American Fisheries Society 115:114.

Post, J. R., and E. A. Parkinson. 2001. Energy allocation strategy in young fish: allometry and survival. Ecology 82:1040-1051.
Pothoven, S. A., and C. P. Madenjian. 2008. Changes in consumption by alewives and lake whitefish after dreissenid mussel invasions in lakes Michigan and Huron. North American Journal of Fisheries Management 28:308-320.

Pothoven, S. A., and H. A. Vanderploeg. 2004. Diet and prey selection of alewives in Lake Michigan: seasonal, depth, and interannual patterns. Transactions of the American Fisheries Society 133:1068-1077.

Rand, P. S., B. F. Lantry, R. O'Gorman, R. W. Owens, and D. J. Stewart. 1994. Energy density and size of pelagic prey fishes in Lake Ontario, 1978-1990: implications for salmonine energetics. Transactions of the American Fisheries Society 123:519-534.

Schultz, E. T., and D. O. Conover. 1997. Latitudinal differences in somatic energy storage: adaptive responses to seasonality in an estuarine fish (Atherinidae: Menidia menidia). Oecologia 109:516-529.

Stewart, D. J., and F. P. Binkowski. 1986. Dynamics of consumption and food conversion by the Lake Michigan alewives: an energetics-modeling synthesis. Transactions of the American Fisheries Society 115:643-661.

Stewart, D. J., and M. Ibarra. 1991. Predation and production by salmonine fishes in Lake Michigan, 1978-1988. Canadian Journal of Fisheries and Aquatic Sciences 48:909-922.

Wells, L. 1970. Effects of alewife predation on zooplankton populations in Lake Michigan. Limnology and Oceanography 15:556-565.

Wuenschel, M. J., A. R. Jugovich, and J. A. Hare. 2006. Estimating the energy density of fish: the importance of ontogeny. Transactions of the American Fisheries Society 135:379-385. 